\title{
Baseline characteristics and outcomes of COVID-19 patients admitted to a Respiratory Intensive Care Unit (RICU) in Southern Italy
}

\author{
Valentina Di Lecce, ${ }^{1}$ Giovanna Elisiana Carpagnano, ${ }^{1}$ Paola Pierucci, ${ }^{1}$ Vitaliano Nicola Quaranta, ${ }^{2}$ \\ Federica Barratta, ${ }^{1}$ Annapaola Zito, ${ }^{3}$ Enrico Buonamico, ${ }^{1}$ Onofrio Resta ${ }^{1}$ \\ ${ }^{1}$ Institute of Respiratory Disease, Department of Basic Medical Science, Neuroscience, and Sense Organs, University of Bari \\ “Aldo Moro", Bari \\ ${ }^{2}$ Pneumology Department, "Di Venere" Hospital Bari \\ ${ }^{3}$ Cardiology Department, "SS Annunziata" Hospital, Taranto, Italy
}

\begin{abstract}
The recent Coronavirus disease 19 (COVID-19) pandemic, first in China and then also in Italy, brought to the attention the problem of the saturation of Intensive Care Units (ICUs). Almost all previous reports showed that in ICU less than half of patients were treated with invasive mechanical ventilation (IMV) and the rest of them with non-invasive respiratory support. This highlighted the role of respiratory intensive care units (RICUs), where patients with moderate to severe respiratory failure can be treated with non-invasive respiratory support, avoiding ICU admission.

In this report, we describe baseline characteristics and clinical outcomes of 97 patients with moderate to severe respiratory failure due to COVID-19 admitted to the RICU of the Policlinico of Bari from March $11^{\text {th }}$ to May $31^{\text {st }} 2020$. In our population, most of the subjects were male $(72 \%)$, non-smokers $(76 \%)$, with a mean age of $69.65 \pm 14$ years. Ninety-one percent of patients presented at least one comorbidity and $60 \%$ had more than two comorbidities. At admission, $40 \%$ of patients showed $\mathrm{PaO}_{2} / \mathrm{FiO}_{2}$ ratio between 100 and 200 and $17 \%$ showed $\mathrm{PaO}_{2} / \mathrm{FiO}_{2}$ ratio $<100$. Mean $\mathrm{Pa}_{2} / \mathrm{FiO}_{2}$ ratio at admission was $186.4 \pm 80$. These patients were treated with non-invasive respiratory support $40 \%$ with CPAP, $38 \%$ with BPAP, $3 \%$ with HFNC, $11 \%$ with standard oxygen therapy or with IMV through tracheostomy (patients in step down from ICU, 8\%). Patients discharged to general ward (GW) were 51\%, 30\% were transferred to ICU and $19 \%$ died.

To the best of our knowledge, this is one of the few described experiences of patients with respiratory failure due to COVID-19 treated outside the ICU, in a RICU. Outcomes of our patients, characterized by several risk factors for disease progression, were satisfactory compared with other experiences regarding patients treated with non-invasive respiratory support in ICU. The strategical allocation of our RICU, between ED and ICU, might have positively influenced clinical outcomes of our patients.
\end{abstract}

Correspondence: Valentina Di Lecce, Institute of Respiratory Disease, Department of Basic Medical Science, Neuroscience, and Sense Organs, University of Bari “Aldo Moro", Bari, Italy

E-mail: valentina.dilecce89@gmail.com

Contributions: VDL, GEC, EB and OR, made substantial contribution to the conception and design of the work, VDL, EB, $\mathrm{PP}$ and $\mathrm{FB}$, to the data acquisition, VDL, EB, VQ, to the analysis, and VQ, PP, GEC, OR to the interpretation. VDL, EB, OR helped in drafting the article and OR revised it critically for important intellectual content. All authors gave their final approval of the version to be published and agreed for the accuracy or integrity of any part of the work.

Conflict of interest: The authors declare no conflict of interest.

Funding: None.

Availability of data and materials: Research data are stored in the hospital database.

Ethicals approval and consent to partecipate: The Institutional Review Board of teaching hospital Policlinico of Bari approved this study (Ethical Committee number: 6380) and due to the nature of retrospective study, waived the need for informed consent from individual patients.

Consent for publication: Not applicable. 


\section{Introduction}

Since December 2019, the world is in the grip of the Coronavirus Disease 19 (COVID-19). The clinical spectrum of this infection, caused by the Severe Acute Respiratory Syndrome Coronavirus 2 (SARS-CoV-2), appears to be wide, encompassing asymptomatic infection, mild upper respiratory tract illness and severe viral pneumonia with acute respiratory failure (ARF), needing admission to intensive care units (ICU) in a high proportion of cases [1]. This brought to the worldwide attention the problem of ICU saturation, which negatively affected patient survival.

Data from China, where SARS-CoV-2 spread firstly, show that the percentage of patients who required admission to ICU varied from $5 \%$ to $32 \%$ [2]. Furthermore, as reported in a recent study by Grasselli et al., in Chinese ICUs invasive mechanical ventilation (IMV) was performed only in less than half of patients, and noninvasive ventilation (NIV) and high flow nasal cannula (HFNC) were used much more frequently than in other hospital wards $[3,4]$. This highlighted the role of respiratory intensive care units (RICUs), where patients with moderate to severe respiratory failure can be treated with non-invasive respiratory support, avoiding ICU admission. However, COVID-19 patients with ARF may rapidly develop severe respiratory distress, needing suddenly intubation and transfer to ICU. Thus, another important aspect to consider in the COVID-19 hospitals emergency plans is the location of the RICU.

In this report, we described baseline characteristics and outcomes of patients with moderate to severe ARF due to COVID-19 admitted to the RICU of a large university hospital in Southern Italy.

\section{Design and Methods}

This is a retrospective, observational single centre study. We obtained medical records and compiled data from hospitalized adult inpatients, affected by moderate to severe ARF due to COVID-19 related pneumonia, that were in our RICU of Teaching Hospital "Policlinico" of Bari from March $11^{\text {th }}$ to May 31 $1^{\text {st }} 2020$. To stage the severity of acute respiratory failure we used the classification provided in the Berlin definition for Acute Respiratory Distress Syndrome (ARDS): mild, with $200 \mathrm{~mm} \mathrm{Hg}<\mathrm{PaO}_{2} / \mathrm{FIO}_{2} \leq 300 \mathrm{~mm}$ $\mathrm{Hg}$; moderate, with $100 \mathrm{~mm} \mathrm{Hg}<\mathrm{PaO}_{2} / \mathrm{FIO}_{2} \leq 200 \mathrm{~mm} \mathrm{Hg}$; severe, with $\mathrm{PaO}_{2} / \mathrm{FIO}_{2} \leq 100 \mathrm{~mm} \mathrm{Hg}$ [6]. All consecutive patients with laboratory confirm of SARS-Cov-2 infection, on the basis of the WHO interim guidance [5], referred to emergency department (ED) and subsequently admitted in general ward (GW), in RICU or in ICU accordingly to disease severity and grade of respiratory insufficiency, from the study group. In ICU only patients with very severe ARF were admitted, requiring prompt intubation, and showing clinical signs or symptoms that did not allow non-invasive approach [7]. In our hospital, ICU and RICU were located in the same building, on the same floor across the corridor.

The Institutional Review Board of Teaching Hospital Policlinico of Bari approved this study (Ethical Committee number: 6380) and due to the nature of retrospective study, waived the need for informed consent from individual patients.

Data were expressed as mean and standard deviation (SD) if they were normally distributed while when categorical variables as count $(\%)$.

\section{Results}

Baseline characteristics and clinical outcomes are shown in Table 1 . The study population included 97 hospitalized patients.
Men were more represented than women (72\% vs 28\%). Mean age was $69.65 \pm 14$ years. Female population mean age ( $74.70 \pm$ years) was significantly higher compared to male population mean age (67.64 \pm 14 years). Twenty seven percent of subjects were obese. It is worth noting that almost all patients were never smokers or ex-smokers from more than 15 years $(96 \%)$; only $4 \%$ of patients were current smokers. Most of the patients presented at least one comorbidity (91\%), and over half had more than two comorbidities $(60 \%)$. Main comorbidity was hypertension (64.5\%), followed by cardiovascular diseases $(54.5 \%)$, kidney disease $(47.4 \%)$ and diabetes mellitus (30.5\%). Pulmonary comorbidities were not common (8.3\%). At admission, $98 \%$ of patients showed higher Creactive protein (CRP), $89 \%$ had higher D-dimer, $75 \%$ had higher Lactate dehydrogenase (LDH), and 72\% showed lymphopenia. Mean CRP was $117.99 \pm 79.52$, mean D-dimer 2428.82 \pm 3794.27 , mean LDH $333.73 \pm 108.82$ and mean number of peripheral lymphocyte cells $948.41 \pm 662.64$.

Regarding pharmacological treatments, 80 patients $(83 \%)$ underwent anticoagulant therapy with Enoxaparin, out of whom 18 (22.5\%) at prophylactic dose and $62(77.5 \%)$ at therapeutic dose, following evidence of D-Dimer increase or CT finding of pulmonary perfusion defects. Seventy-nine patients $(81 \%)$ underwent antibiotic therapy, out of whom 65 assumed azithromycin, and 35 patients $(36 \%)$ underwent antiviral therapy with lopinavir/ritonavir (while no one assumed remdesivir, unavailable at our Hospital at that time). Seventy-one patients (73\%) were treated with hydroxychloroquine, and 6 patients $(6 \%)$ with tocilizumab. Finally, 25 patients $(26 \%)$ assumed corticosteroids.

Moderate to severe ARF affected most of our patients (77\%) at admission: $40 \%$ of patients showed a $\mathrm{PaO}_{2} / \mathrm{FiO}_{2}$ ratio between 100 and 200 and $17 \%<100$. Mean $\mathrm{PaO}_{2} / \mathrm{FiO}_{2}$ ratio was $186.4 \pm 80$. Twenty-six percent of patients dead in RICU had severe ARF at admission, $32 \%$ moderate and $32 \%$ mild; mean $\mathrm{PaO}_{2} / \mathrm{FiO}_{2}$ ratio of patients dead in RICU was $176.67 \pm 92.36$. The $18 \%$ of patients transferred to ICU had severe ARF at admission, $43 \%$ moderate and $25 \%$ mild; mean $\mathrm{PaO}_{2} / \mathrm{FiO}_{2}$ ratio was $191.26 \pm 114.10$.

In regard to the level of respiratory support needed during hospitalization, $11 \%$ of our patients underwent low flow oxygen therapy, 3\% high flow oxygen therapy delivered with HFNC, and $86 \%$ NIV [ $40 \%$ by continuous positive airway pressure (CPAP) and $38 \%$ by bilevel positive airway pressure (BPAP)]. Finally, eight percent of patients in step down from ICU was treated with invasive mechanical ventilation (IMV) through tracheostomy.

Forty-nine (51\%) patients were discharged to a lower intensity care ward (GW), 29 patients (30\%) were transferred to ICU in stepup, and 19 patients (19\%) died in RICU.

\section{Discussion}

This retrospective observational single center study reports data about patients with moderate to severe ARF due to COVID-19, treated in a RICU. In this sample, there was a higher prevalence of males within admitted patients $(72 \%)$. Male patients mean age was significantly lower than in females, thus leading to the hypothesis that COVID-19 infection favors male younger patients. Only a few studies on COVID-19 pandemic considered age and gender distribution in dead COVID-19 patients. Xie and colleagues found similar findings [8], as female patients were usually affected at older age. Our population mean age was higher than in other studies $[2,3,9]$. This is an important feature to consider, because in previous studies older age has been reported as an important independent predictor of mortality in SARS and MERS infections [10,11]. Similarly, Zhou and colleagues suggested that an older age might be associated with higher death rate in patients with COVID-19 [1]. 
Another important point of the present study was that a higher number of comorbidities, comparing to other studies, characterized our population $[2,4]$. On the other hand, as showed by Zhou and colleagues in a retrospective cohort study conducted in Wuhan, the odds ratio of hospital death was higher in patients with a higher comorbidity number, especially diabetes mellitus and coronary artery disease [1]. From the standpoint of the laboratory findings, it is not surprising that we found high level of LDH and CRP, which was very common in patients hospitalized for COVID-19 [12,13]. Indeed, those values were considered as potential pathognomonic features of suspect COVID-19 patients [14], and their levels were higher in severe and very severe infected patients [15]. Together with the presence of comorbidities, the older age and the lymphopenia, high level of LDH was considered as an independent risk factor for progression of COVID-19 disease in a Chinese single center study that proposes a score model for the stratification of risk in COVID-19 patients named CALL, based on these factors [16]. Therefore, our population is characterized by the presence of all the known risk factors for disease progression.

To the best of our knowledge, this is one of the few described experiences about patients with respiratory failure due to COVID19, treated outside the ICU, in a RICU. Since March 2020, the Policlinico of Bari in Southern Italy was transformed in a COVID19 Hospital. In RICU, patients referred to ED with acute respiratory failure due to COVID-19 but without need of intubation and invasive ventilation in ICU were admitted. During the stay in our RICU, patients underwent to non-invasive respiratory support provided by CPAP (40\%), BPAP (38\%) and HFNC (3\%); $11 \%$ of

Table 1. Baseline characteristics and clinical outcomes of patients.

\begin{tabular}{|c|c|}
\hline Patients (n) & 97 \\
\hline $\operatorname{Sex}(M / F, \%)$ & $72 / 28$ \\
\hline Age (years, mean, SD) & $69.65 \pm 14$ \\
\hline $\begin{array}{l}\text { Smoking habit (\%): } \\
\text { - } \quad \text { Non smokers } \\
\text { - } \quad \text { Current smokers }\end{array}$ & $\begin{array}{c}96 \\
4\end{array}$ \\
\hline $\begin{array}{ll}\text { Patients with at least } 1 \text { comorbidity (\% of pts) } \\
\text { - } & \text { Hypertension } \\
\text { - } & \text { Cardiovascular disease } \\
\text { - } & \text { Chronic kidney disease } \\
\text { - } & \text { Respiratory disease } \\
\end{array}$ & $\begin{array}{c}91 \\
64.5 \\
54.5 \\
47.4 \\
30.5 \\
8.3 \\
\end{array}$ \\
\hline Patients with 2 comorbidities (\% of pts) & 60 \\
\hline $\begin{array}{l}\text { Acute respiratory failure }(\% \text { of pts) } \\
\text { Moderate }(200<\mathrm{P} / \mathrm{F}<100) \\
\text { Severe }(\mathrm{P} / \mathrm{F}<100)\end{array}$ & $\begin{array}{l}40 \\
17\end{array}$ \\
\hline Mean $\mathrm{PaO}_{2} / \mathrm{FiO}_{2}$ & $186 \pm 80$ \\
\hline $\begin{array}{l}\text { Non-invasive respiratory support (\% of pts) } \\
\text { Low flow oxygen therapy } \\
\text { HFNC } \\
\text { CPAP } \\
\text { BPAP } \\
\text { IMV through tracheostomy }\end{array}$ & $\begin{array}{c}11 \\
3 \\
40 \\
38 \\
8\end{array}$ \\
\hline $\begin{array}{l}\text { Clinical outcomes (\% of pts) } \\
\text { Discharged to GW } \\
\text { Transferred to ICU } \\
\text { Dead in RICU }\end{array}$ & $\begin{array}{l}51 \\
30 \\
19\end{array}$ \\
\hline
\end{tabular}

$\mathrm{PaO}_{2} / \mathrm{FiO}_{2}$, arterial oxygen partial pressure to fractional inspired oxygen; HFNC, high-flow nasal cannula; CPAP, continuous positive airway pressure; BPAP, bilevel positive airway pressure; IMV, invasive mechanical ventilation; GW, general ward; ICU, intensive care unit; RICU, respiratory intermediate care unit. patients were treated with low flow oxygen therapy. Only $8 \%$ of patients, in step down from ICU, underwent IMV.

The role of non-invasive respiratory support for severe COVID19 patients is currently a subject of major debate [7]. Similarly, the role of RICU in COVID-19 pandemic has not been clarified. Much of the data guiding practice in this area derived from the critical care setting for ARDS. In this subtype of patients, characterized by a $\mathrm{PaO}_{2} / \mathrm{FiO}_{2}$ ratio $<150$, intubation gave a higher survival benefit compared to NIV [11]. Only one study, performed during SARS epidemic, demonstrated that NIV might avoid intubation, while there is a lack of other studies supporting this evidence [12]. Considering the resource limitations imposed by COVID-19 pandemic, it is important to determine whether selected patients might be treated outside ICU [17]. Another matter of debate is the correct non-invasive respiratory support setting in this kind of patients. HFNC demonstrated to reduce the requirement of intubation in ARF vs NIV in the FLORALI trial [18], but regarding COVID-19 the need of reducing airflow to avoid viral droplet dispersion, and to mitigate the infection risk in hospital ward leads to not understand the real benefits related to this technique.

Furthermore, COVID-19 patients with ARF show a good tolerance to high positive end-expiratory pressure (PEEP) normally obtainable with CPAP, related to atelectatic lung areas recruitment and reduced work-of-breathing. Benefits from the addition of an inspiratory pressure support, in BPAP NIV, is less known. However, the optimal mode of respiratory support in COVID-19 patients has not been stated yet, but it is important to know which damage can be caused if inappropriate treatment is used [17]. Therefore, it is fundamental to remark the need of avoiding delays in intubation and IMV start. At this regard, we decided to allocate our RICU strategically near the ICU. From the beginning of the COVID-19 pandemic in Italy, the Policlinico Hospital of Bari, one of the main COVID-19 dedicated hospitals in the Apulia region, created a strategic emergency plan moving the Department of Respiratory Medicine and the ICU into the same COVID-19 building. ICU and RICU were located on the same floor across the corridor to facilitate and to speed the fluid transit of patients from one Unit to the other one. Every day, intensivists were rounding together with respiratory physicians to appropriately address the need of increased care and vice versa. This allowed to minimize intubation time, also giving the possibility to have a continuous collaboration and to decide, in short times, pathways for patients who suddenly deteriorated.

There are currently no drugs registered to treat COVID-19, and a vaccine is not available yet. Therefore, management is mainly based on the treatment of symptoms, on the attempt to prevent ARF and, in the event of its onset, on supportive treatments. As for the drugs used in clinical practice, our data are in line with those reported in the studies conducted in the same period $[19,20]$. These still involve the use of antivirals such as lopinavir / ritonavir and hydroxychloroquine, not present in the recently published guidelines by the America Thoracic Society (ATS) / European Respiratory Society (ERS) task force [21].

Regarding clinical outcomes, our data are in line with those shown in a recent report by Henchi and colleagues about the organization of the Sub-Intensive Respiratory Unit of Lodi Hospital in Northern Italy. Indeed, in our RICU, $51 \%$ of patients admitted were discharged to GW, 30\% was transferred to ICU and 19\% died. Instead, in Lodi experience, $64 \%$ of patients were discharged, $18 \%$ were transferred to ICU and $18 \%$ died [22]. However, a comparison with the characteristics of COVID-19 patients treated in Lodi SubIntensive Respiratory Unit was not possible, because the data about the severity of patients' clinical conditions are not reported. Therefore, the only comparison possible was with the number of COVID-19 patients treated with non-invasive mechanical ventilation in ICU. Zhou and colleagues analyzed 191 patients hospitalized, of which $50(26 \%)$ were admitted to ICU, where 26 
patients (51\% of the ICU patients) underwent to NIV and $24(47 \%$ of the ICU patients) died (data about $\mathrm{PaO}_{2} / \mathrm{FiO}_{2}$ ratio are not reported) [1]. Wang and colleagues evaluated 138 patients hospitalized, out of which 36 were admitted to ICU, where 15 patients (42\% of ICU patients) underwent to NIV and $6(17 \%$ of the ICU patients) died [median $\mathrm{PaO}_{2} / \mathrm{FiO}_{2}$ ratio 136 (IQR 103-234)] [4]. Yang and colleagues analyzed 52 critical ill patients hospitalized, out of which 29 patients (56\%) underwent to NIV and 23 (44\%) died (data about $\mathrm{PaO}_{2} / \mathrm{FiO}_{2}$ ratio are not reported) [20]. Therefore, our study may suggest that satisfactory results can be obtained also in different context, outside the ICU, with less cost and lower risk of complication related to ICU hospitalization. However, these data need confirmation on a larger sample of patients and on a greater number of experiences in RICU.

\section{Conclusions}

This report shows data about patients with ARF due to COVID19 treated with non-invasive respiratory support in a RICU of a large university hospital in Southern Italy. To the best of our knowledge, this is one of the few described experience that supports the role of RICUs in the management of these patients. Moreover, the strategical allocation of our RICU in the same building between ED and ICU might have played an important role in positively influencing the clinical outcomes of the observed population, made up by patients affected by a large number of risk factors for negative outcomes.

\section{Acknowledgment}

The authors would like to thank Dr Boniello, Dr Carrassi, Dr Diaferia, Dr Dimitri, Dr Di Gioia, Dr Labate, Dr Majorano, Dr Palumbo, Dr Portacci, Dr Santomasi, and Dr Valerio for their contribution in the study.

\section{References}

1. Zhou F, Yu T, Du R, Fan G, Liu Y, Liu Z, et al. Clinical course and risk factors for mortality of adult inpatients with COVID-19 in Wuhan, China: a retrospective cohort study. Lancet 2020;395:105462.

2. Guan W, Ni Z, Hu Yu, Liang W, Ou C, He J, et al. Clinical characteristics of coronavirus disease 2019 in China. N Engl J Med 2020;382:1708-20.

3. Grasselli G, Zangrillo A, Zanella A, Antonelli M, Cabrini L, Castelli A, et al. Baseline Characteristics and Outcomes of 1591 Patients Infected With SARS-CoV-2 Admitted to ICUs of the Lombardy Region, Italy. JAMA 2020; 323:1574-81.

4. Wang $\mathrm{D}, \mathrm{Hu} \mathrm{B}, \mathrm{Hu} \mathrm{C}, \mathrm{Zhu} \mathrm{F}$, Liu X, Zhang J, et al. Clinical characteristics of 138 hospitalized patients with 2019 novel coronavirus-infected pneumonia in Wuhan, China. JAMA 2020;323:1061-9.

5. WHO. Coronavirus disease (COVID-19) outbreak. Accessed: 11 Mar 2019. Available from: https://www.who.int/ emergencies/ diseases/novel-coronavirus-2019/situation-reports

6. ARDS Definition Task Force, Ranieri VM, Rubenfeld GD, Thompson BT, Ferguson ND, Caldwell E, et al. Acute respiratory distress syndrome: the Berlin definition. JAMA 2012;307:2526-33.

7. Higgs A, McGrath BA, Goddard C, Rangasami J, Suntharalingam $\mathrm{G}$, Gale R, et al. Guidelines for the management of tracheal intubation in critically ill adults. Br J Anaesth 2018;120:323-52.

8. Xie J, Tong Z, Guan X, Du B, Qiu H. Clinical Characteristics of patients who died of Coronavirus Disease 2019 in China. JAMA Netw Open 2020;3:e205619.

9. Bhatraju PK, Ghassemieh BJ, Nichols M, Kim R, Jerome KR, Nalla AK, et al. Covid-19 in critically ill patients in the Seattle region Case series. N Engl J Med 2020;382:2012-22.

10. Choi KW, Chau TN, Tsang O, Tso E, Chiu MC, Tong WL, et al. Outcomes and prognostic factors in 267 patients with severe acute respiratory syndrome in Hong Kong. Ann Intern Med 2003;139: 715-23.

11. Hong KH, Choi JP, Hong SH, Lee J, Kwon J-S, Kim S-M, et al. Predictors of mortality in Middle East respiratory syndrome (MERS). Thorax 2018;73:286-9.

12. Aggarwal S, Garcia-Telles N, Aggarwal G, Lavie C, Lippi G, Henry BM. Clinical features, laboratory characteristics, and outcomes of patients hospitalized with Coronavirus Disease 2019 (COVID-19): Early report from the United States. Diagnosis (Berl) 2020;7:91-6.

13. Fu L, Wang B, Yuan T, Chen X, Ao Y, Fitzpatrick T, et al. Clinical characteristics of Coronavirus Disease 2019 (COVID-19) in China: A systematic review and meta-analysis. J Infect 2020;80:656-665

14. Ferrari D, Motta A, Strollo M, Banfi G, Locatelli M. Routine blood tests as a potential diagnostic tool for COVID-19. Clin Chem Lab Med 2020;58:1095-1099.

15. Wang F, Hou H, Luo Y, Tang G, Wu S, Huang M, et al. The laboratory tests and host immunity of COVID-19 patients with different severity of illness. JCI Insight 2020;5:e137799.

16. Ji D, Zhang D, Xu J, Chen Z, Yang T, Zhao P, et al. Prediction for progression risk in patients with COVID-19 pneumonia: The CALL score. Clin Infect Dis 2020;71:1393-9.

17. McEnery T, Gough C, Costello RW. COVID-19: Respiratory support outside the intensive care unit. Lancet Respir Med 2020;8:538-9.

18. Frat JP Thille AW, Mercat A, Girault C, Ragot S, Perbet S, et al. High-flow oxygen through nasal cannula in acute hypoxemic respiratory failure. N Engl J Med 2015;372:2185-96.

19. Huang C, Wang Y, Li X, Ren L, Zhao J, Hu Y, Zhang L, et al. Clinical features of patients infected with 2019 novel coronavirus in Wuhan, China. Lancet 2020;395:497-506.

20. Yang X, Yu Y, Xu J, Shu H, Xia J, Liu H, et al. Clinical course and outcomes of critically ill patients with SARS-CoV-2 pneumonia in Wuhan, China: a single-centered, retrospective, observational study. Lancet Respir Med 2020;8:475-81.

21. Bai C, Chotirmall SH, Rello J, Alba GA, Ginns LC, Krishnan JA, et al. Updated guidance on the management of COVID-19: from an American Thoracic Society/European Respiratory Society coordinated International Task Force (29 July 2020). Eur Respir Rev 2020;29:200287.

22. Henchi S, Conti CB, Vanoni N, Repossi AC, Cipolla G, Marra M, et al. First COVID-9 sub-intensive respiratory unit in Europe: the Italian experience. Multidiscip Respir Med 2020;15:682. doi: $10.4081 / \mathrm{mrm} .2020 .682$

Received for publication: 28 July 2020. Accepted for publication: 15 September 2020.

This work is licensed under a Creative Commons Attribution-NonCommercial 4.0 International License (CC BY-NC 4.0).

(C) Copyright: the Author(s), 2020

Licensee PAGEPress, Italy

Multidisciplinary Respiratory Medicine 2020; 15:704

doi:10.4081/mrm.2020.704 